\title{
A simplified creep-reverse plasticity solution method for bodies subjected to cyclic loading
}

\author{
Haofeng Chen and Alan R.S. Ponter \\ Department of Engineering, University of Leicester, Leicester, LE1 7RH, UK \\ Email: hfc3@1e.ac.uk, asp@,le.ac.uk
}

Tel: 0044-1162522549 Fax: 0044-116252252

\begin{abstract}
An extension of the upper bound shakedown theorem to load histories in excess of shakedown has been applied recently to the evaluation of a ratchet limit and the varying plastic strain magnitudes associated with a varying residual stress field. Solutions were obtained by the Linear Matching Method. In the present paper, this technique is extended to the evaluation of creep-reverse plasticity mechanism for bodies subjected to thermal cyclic loading including creep effects. The accumulated creep strain, the varying flow stress and the corresponding varying residual stress field during a creep dwell time are evaluated as well as the elastic follow-up factor. Three alternative computational strategies are discussed with differing but related assumptions. The problem of a plate with a central circular hole is discussed, subjected to cyclic thermal load. All three methods provide similar values for the elastic follow-up factor, indicating that the result is insensitive to the range of assumptions made. The simplest method, Method 1, is suggested as the basis of a general purpose method for use in life assessment.
\end{abstract}

Keywords: cyclic loading, creep, reverse plasticity, elastic follow-up

\section{NOTATION}

Z

elastic follow-up factor 
$E, \bar{E} \quad$ Young's modulus and effective modulus for uni-axial and multi-axial conditions

$\sigma, \mathcal{\text { stress and strain }}$

$t, d t, \tau \quad$ times

$t_{1}, t_{2}, \Delta t \quad$ time instances and creep dwell time

$\Delta \varepsilon^{p}, \Delta \varepsilon^{c} \quad$ plastic strain range and accumulated creep strain

$\Delta \rho^{p}, \Delta \rho^{c} \quad$ varying residual stress associated with reverse plasticity mechanism and creep

relaxation

$\Delta \varepsilon_{i j}^{r p} \quad$ total varying strain

$D_{c}, N_{0} \quad$ creep endurance limit and cycles to failure

$\hat{\sigma}_{i j} \quad$ applied linear elastic stress field

$\bar{\rho}_{i j}, \rho_{i j}(t) \quad$ constant and changing residual stress field

$\mu, K \quad$ Linear elastic shear modulus and modulus of compression

$\Delta u_{i}^{p r} \quad$ displacement increment

$\sigma^{c}, \Delta \varepsilon_{i j}^{c} \quad$ creep stress and creep strain

$\sigma_{0}, \dot{\varepsilon}_{0}, \mathrm{n} \quad$ creep materials data

$\dot{\varepsilon}_{i j}^{c} \quad$ creep strain rate

$\theta, \theta_{0}, \Delta \theta \quad$ temperatures

E, S, P, R elastic, shakedown, reverse plasticity and ratchetting region

$\bar{\sigma}, \overline{\dot{\varepsilon}} \quad$ von Mises effective stress and strain rate

$\sigma_{i j}^{i n} \quad$ initial stress field for creep computation

$D, L \quad$ diameter of the hole and length of the plate

$\sigma_{t 0} \quad$ maximum von Mises effective elastic thermal stress

$\sigma_{Y}, v \quad$ yield stress and Poison's ratio

$a, r \quad$ radius of the hole and distance to the centre of hole 


\section{Introduction}

The processes of engineering design and life assessment of structures subjected to cyclic loading require the evaluation of load histories for which certain types of material failure occur (Ainsworth, 2003; Ainsworth and Budden, 1992). The prediction of these failure mechanisms of structures with variable repeated loading is significant and has attracted the attentions of many researchers (Chen and Ponter, 2001a, 2001b; Chen et al., 1999, 2003; Engelhardt, 1999; Ponter and Chen, 2001; Maier, 1977; Corradi and Zavelani, 1974; Hachemi and Weichert, 1998; Mackenzie et al., 1996; Seshadri and Mangalaramanan, 1998; Boyle et al., 1997) generally using programming methods.

One of the most successful of such methods, the Linear Matching Method (LMM) (Chen and Ponter, 2001a, 2001b; Chen et al., 2003; Engelhardt, 1999; Ponter and Chen, 2001) has been applied with considerable rigor to cyclic loading problems where the residual stress field remains constant. This includes the evaluation of classical limit loads, shakedown limits, creep ruptures and rapid cycle creep solutions (Chen and Ponter, 2001a; Chen et al., 2003; Engelhardt, 1999). The LM method has also been extended to cases where the residual stress field changes during a cyclic state. This includes the assessment of the plastic strain amplitude and ratchet limit associated with reverse plasticity mechanisms (Chen and Ponter, 2001b; Ponter and Chen, 2001) when the load history is in excess of shakedown but less than a ratchet limit. In these circumstances there are two properties required in low temperature design and life assessment. The amplitude of plastic strain provides information concerning fatigue crack initiation in low cycle fatigue and the capacity of the body to withstand additional constant mechanical load indicates the proximity to a ratchet limit. In (Ponter and Chen, 2001; Chen and Ponter, 2001b) a programming method, the Linear Matching Method has been used to characterise both the strain 
amplitude and the proximity to a ratchet limit, based upon a new minimum theorem (Ponter and Chen, 2001).

In practice, components can operate at high temperature within the creep range both within shakedown and for load ranges in excess of shakedown. Typically, in power plant, a creep dwell periods exist where the temperature of some proportion of the structure lies within the creep range. For some components, e.g. heat exchangers, the mechanical loads can be relatively small but the thermal stresses can be significantly in excess of yield. In such circumstances creep strains occur, and this results in the relaxation of initially high stresses as creep strains replaces elastic strains. Lifetime integrity may then be limited not only by low cycle fatigue but the damaging effects of the creep strains produced during creep relaxation. The evaluation of the creep relaxation, the determination of the accumulated creep strain, the varying flow stress and the corresponding elastic follow-up factors during dwell period are very important components of life assessment methods. The work of this paper is part of a general study of the application of the Linear Matching Method to the various stages of Life Assessment methods, using R5 (Ainsworth, 2003; Ainsworth and Budden, 1992) as the beginning point. It is anticipated that such methods may then replace the rule-based methods currently used, providing more accurate and less conservative predictions.

The term "elastic follow-up" has been used to describe the effects of creep strains in local regions where the total strain increases through interaction with the overall elastic compliance of the structure (Ainsworth, 2003). The concept was introduced to allow the local accumulation of creep strain to be estimated without the need to performing full time-dependent structural analysis. The process may be described for a uniaxial state of stress by an equation of the form:

$$
\frac{d \varepsilon_{c}}{d t}+\frac{Z}{E} \frac{d \sigma}{d t}=0
$$


where $\mathrm{Z}$ is the elastic follow-up factor, E is Young's modulus, $\varepsilon_{c}$ is the creep strain accumulated during the dwell, and $\sigma$ is the applied stress. The factor $\mathrm{Z}$ characterises the stress-strain path followed during stress relaxation. For example, $Z=1$ corresponds to relaxation at a constant total strain and $Z \rightarrow \infty$ corresponds to creep at a constant stress. Although equation (1) is an approximation, in detailed calculations of relaxation, $\mathrm{Z}$ is found to be relatively constant in time.

For a restricted class of problems, where the stress relaxes proportionally throughout the structure, an analytic solution for Z may be computed. All of the known solutions are of this type (Hubel and Zeibig, 1996). In Appendix 1 we give a general derivation of this result and apply the result to three simple examples where creep occurs throughout the structure or, alternatively, in only part of the structure. These solutions demonstrate that the variation of $\mathrm{Z}$ values between otherwise similar structures can be significant. Accurate assessments of $Z$ and creep accumulation may only be achieved through an accurate description of the initial stress and the variation of the creep rate throughout the structure during the dwell period.

The primary objective of this paper is to investigate the possibility of extending the reverse plasticity method of (Ponter and Chen, 2001; Chen and Ponter, 2001b) to allow for creep relaxation during a dwell period, giving a composite method that yields the plastic strain amplitude, cyclic strain due to creep and an estimate of $\mathrm{Z}$. In this way all the significant features of the structural problem may be included without the need of a full step-by-step analysis. In fact we describe three alternative methods, Methods 1 to 3, based on related but differing assumptions. We find that that they all produce virtually identical values of $Z$, implying that its value is not particularly sensitive to the range of assumptions. This suggests that method 1 , the computationally most efficient, may well form the basis for an efficient computational technique for use in life assessment techniques. 


\section{Elastic Follow-up factor $\mathrm{Z}$ for Proportional Relaxation}

For certain simple problems the stress relaxes according to the simple equation

$$
\sigma_{i j}(t)=\sigma_{i j}^{0} f(t)
$$

where $\sigma_{i j}^{0}$ is the stress at time $\mathrm{t}=0$. In this case $\mathrm{Z}$ may be evaluated explicitly;

$$
Z=\frac{2 \widetilde{U}}{\widetilde{\dot{D}}^{c}}
$$

where $\widetilde{U}$ is the total elastic strain energy and $\widetilde{\dot{D}}^{c}$ is the total creep energy dissipation rate, both evaluated for $\sigma_{i j}^{0}$. Each quantity is normalised with respect to the stress at the location where $\mathrm{Z}$ is required, usually the position of maximum von Mises effective stress. The derivation of this result is given in Appendix 1. A valuable insight into the dependence of $\mathrm{Z}$ on the characteristics of the problem is also provided.

Using these formulations in Appendix 1, we can evaluate $\mathrm{Z}$ for simple beam structures. Table 1 lists the variation of $\mathrm{Z}$ for two simple beam structures with creep index $\mathrm{n}$. The detailed analysis is given in Appendix 2. Generally $\mathrm{Z}$ increases with $\mathrm{n}$ but there are significant differences in behaviour. For a typical value of $n=5, Z$ has values across the range $1.3 \leq Z \leq 4.47$. From these results we observe that an accurate assessment of $\mathrm{Z}$ is only possible if the initial stress is modelled effectively and the variation of the creep rate throughout the structure is properly modelled. The methods described in the next section are designed to achieve these ends.

\section{Definition of the problem}

In order to simplify the problem, the following assumptions are made; there are only two distinct extremes to the elastic solution, at times $t=t_{l}$ and $t_{2}$, a von Mises yield condition applies 
and the elastic behaviour is isotropic. A schematic of a typical load history is shown in Fig.1. The structure is subjected to high temperature into the creep range, beginning at time $t_{1}$ followed by a dwell period $\Delta t$ and then a return to low temperatures at times $t_{2}$. Hence creep relaxation occurs in the body during dwell period $\Delta t$ and reverse plasticity appears in the body at times $t_{1}$ and $t_{2}$. This paper discusses two kinds of creep-reverse plasticity mechanisms for the cyclic loads shown in Fig. 1. Fig. 2a shows, schematically, the case where the load range exceeds the reverse plasticity limit, and the plastic strain increment $\Delta \varepsilon_{i j}^{p}$ as well as the associated residual stress range $\Delta \rho_{i j}^{p}$ occurs at both extremes of the load cycle. This is determined before the evaluation of the accumulated creep strain $\Delta \varepsilon_{i j}^{c}$ and the corresponding residual stress $\Delta \rho_{i j}^{c}$ for creep relaxation. The total varying strain $\Delta \varepsilon_{i j}^{r p}$ is the summation of $\Delta \varepsilon_{i j}^{p}$ and $\Delta \varepsilon_{i j}^{c}$. Fig. 2b shows the case where the load variation is below the elastic shakedown limit, i.e. $\Delta \varepsilon_{i j}^{p}=0, \Delta \rho_{i j}^{p}=0$, and the total varying strain $\Delta \varepsilon_{i j}^{r p}=\Delta \varepsilon_{i j}^{c}$ in the steady state. In order to understand the difference between pure reverse plasticity mechanism (Ponter and Chen, 2001; Chen and Ponter, 2001b) and creep-reverse plasticity mechanism proposed in this paper, Fig. 3 presents a schematic representation of the plastic and creep quantities in the above two mechanisms in biaxial stress space. For the pure reverse plasticity mechanism (Fig.3a), there are two plastic strain increments associated with two load extremes. For the creep-reverse plasticity mechanism (Fig.3b), the strain increment during loading cycle is split into two increments, i.e. the plastic strain increment and the creep strain increment. Note that the accumulated creep strain $\Delta \varepsilon_{i j}^{c}$ is shown as associated with a flow stress surface $\bar{\sigma}=$ constant, and the plastic strains $\Delta \varepsilon_{i j}^{p}$ are associated with the yield surface $\bar{\sigma}=\sigma_{y}$. This corresponds to the simplest of the methods, described in the next section. 
Fig. 4 gives a flow chart for the creep-reverse plasticity solution method. The first step in all three methods is to perform a reverse plasticity solution method (Ponter and Chen, 2001; Chen and Ponter, 2001b) and calculate the varying plastic strain $\Delta \varepsilon_{i j}^{p}$ and the varying residual stress $\Delta \rho_{i j}^{p}$. This step can be ignored (Fig. 2b) when the applied load domain is below the elastic shakedown limit. The second step is to perform a creep-reverse plasticity solution method, where the initial elastic stress amplitude has been amended by the varying residual stress $\Delta \rho_{i j}^{p}$ associated with pure reverse plasticity mechanism. This results in an additional change in residual stress $\Delta \rho_{i j}^{c}$ during the creep dwell $\Delta t$ and an accumulated magnitude of creep strain $\Delta \varepsilon_{i j}^{c}$. The details of how this may be done will be presented in the next several sections. In the context of the life assessment method $\mathrm{R} 5$, once $\Delta \varepsilon_{i j}^{c}$ and the corresponding residual stress $\Delta \rho_{i j}^{c}$ are determined, the elastic follow-up factor $\mathrm{Z}$, the creep endurance limit $D_{c}$, the number of cycles to failure $N_{0}$ induced by low cycle fatigue mechanism can be evaluated and the total damage parameter then be determined thereafter.

\section{The numerical procedure for the varying residual stress field associated with a reverse}

\section{plasticity mechanism}

In (Ponter and Chen, 2001; Chen and Ponter, 2001b), we considered the case when the elastic solution varies, proportionally between two extreme values $\hat{\sigma}_{i j}\left(t_{1}\right)$ and $\hat{\sigma}_{i j}\left(t_{2}\right)$ and describes a straight line path in stress space. The complete steady state solution has a stress history of the general form

$$
\sigma_{i j}(t)=\hat{\sigma}_{i j}(t)+\rho_{i j}(t)+\bar{\rho}_{i j}
$$


where $\bar{\rho}_{i j}$ is a time constant residual stress field corresponding to the residual stress at the beginning of the cycle, and $\rho_{i j}(t)$ is the change of residual stress during the cycle, i.e. $\rho_{i j}(0)=\rho_{i j}(\Delta t)=0$. Within the reverse plasticity regime, the accumulated plastic strain over a cycle is zero and, where plastic yielding occurs, the accumulation of strain consisted of two increments $\Delta \varepsilon_{i j}^{p}$ and $-\Delta \varepsilon_{i j}^{p}$,

$$
\int_{0}^{t_{1}} \dot{\varepsilon}_{i j}^{p} d t=\Delta \varepsilon_{i j}^{p} \text { and } \int_{t_{1}}^{t_{2}} \dot{\varepsilon}_{i j}^{p} d t=-\Delta \varepsilon_{i j}^{p}
$$

The development of these plastic strains results in a change in, $\rho_{i j}(t)$,

$$
\int_{0}^{t_{1}} \rho_{i j} d t=\Delta \rho_{i j}^{p} \text { and } \int_{0}^{t_{1}} \rho_{i j} d t=-\Delta \rho_{i j}^{p}
$$

These increments are related through the elastic properties of the structure. The solution is completed by introducing the simplifying assumption that the total stresses at times $t_{1}$ and $t_{2}$,

$$
\begin{aligned}
& \sigma_{i j}\left(t_{1}\right)=\hat{\sigma}_{i j}\left(t_{1}\right)+\Delta \rho_{i j}+\bar{\rho}_{i j} \\
& \sigma_{i j}\left(t_{2}\right)=\hat{\sigma}_{i j}\left(t_{2}\right)-\Delta \rho_{i j}+\bar{\rho}_{i j}
\end{aligned}
$$

each lies upon the yield surface corresponding to the plastic strains $\Delta \varepsilon_{i j}^{p}$ and $-\Delta \varepsilon_{i j}^{p}$. Comparisons with full step-by-step solutions (Chen and Ponter, 2001b) indicate that the error associated with this assumption is generally small.

In (Ponter and Chen, 2001; Chen and Ponter, 2001b) the problem is posed as a minimisation problem, derived from a general minimum theorem given in (Ponter and Chen, 2001), solved using the Linear Matching Method where a sequence of linear problems converges to the exact solution. The details are given in (Ponter and Chen, 2001; Chen and Ponter, 2001b) and a summary of the resulting algorithm is given below. 
In a typical iteration we begin with an estimate of the plastic strain increment $\Delta \varepsilon_{i j}^{p}=\Delta \varepsilon_{i j}^{i}$ (the solution from the previous iteration) and define the following linear problem for a new estimate $\Delta \varepsilon_{i j}^{p}=\Delta \varepsilon_{i j}^{f}$. A linear coefficient $\bar{\mu}^{i}$ is defined by

$$
2 \sigma_{y}=\left(\frac{3}{2}\right) 2 \bar{\mu}^{i} \bar{\varepsilon}\left(\Delta \varepsilon_{i j}^{c^{i}}\right)
$$

A new distribution $\Delta \varepsilon_{i j}^{f}$ and corresponding $\Delta \rho_{i j}^{f}$ are defined as the solution of the following linear problem;

$$
\begin{gathered}
\Delta \varepsilon_{i j}^{T f^{\prime}}=\frac{1}{2 \mu} \Delta \rho_{i j}^{f^{\prime}}+\Delta \varepsilon_{i j}^{f^{\prime}} \\
\Delta \varepsilon_{k k}^{T f}=\frac{1}{3 K} \Delta \rho_{k k}^{f}
\end{gathered}
$$

and $\Delta \varepsilon_{i j}^{f^{\prime}}=\left(\frac{1}{2 \bar{\mu}^{i}}\right)\left(\Delta \hat{\sigma}_{i j}^{\prime}+\Delta \rho_{i j}^{c f^{\prime}}\right)$

where $\Delta \varepsilon_{i j}^{T f}$ satisfies conditions of compatibility, $\Delta \rho_{i j}^{f}$ satisfies equilibrium conditions and

$$
\Delta \hat{\sigma}_{i j}=\hat{\sigma}_{i j}\left(t_{1}\right)-\hat{\sigma}_{i j}\left(t_{2}\right)
$$

Note that $\Delta \hat{\sigma}_{i j}^{\prime}$ denotes the deviatoric component of $\Delta \hat{\sigma}_{i j}$, etc.

Repeated application of this iterative algorithm provides a sequence of solutions $\Delta \varepsilon_{i j}^{k}$, which converges to the solution that minimises the functional $\bar{I}$ defined in (Ponter and Chen, 2001; Chen and Ponter, 2001b). If we consider two consecutive iterations, $k$ and $(k+1)$, the relationship (7) may be written as;

$$
\bar{\mu}^{k+1}=\bar{\mu}^{k} \frac{2 \sigma_{y}}{\bar{\sigma}\left(\Delta \hat{\sigma}_{i j}+\Delta \rho_{i j}^{k}\right)}
$$


The details of the procedure, as implemented in the commercial finite element code ABAQUS, is given in the appendix of (Chen and Ponter, 2001b). The process is initiated by choosing $\bar{\mu}^{1}=$ constant.

Upon convergence when $\Delta \varepsilon_{i j}^{f}=\Delta \varepsilon_{i j}^{i}$ and $\Delta \rho_{i j}^{f}=\Delta \rho_{i j}^{i}$, it follows from (7) and (10) that

$$
\bar{\sigma}\left(\Delta \hat{\sigma}_{i j}+\Delta \rho_{i j}^{f}\right)=2 \sigma_{y}
$$

i.e. the total stress change in stress lies within the yield surface for a suitable $\bar{\rho}_{i j}$.

There are two properties of this simple solution method that are worthy of note. The solution is entirely concerned with the change in stress over the cycle and is independent of the constant residual stress $\bar{\rho}_{i j}$ and any component of the linear elastic solution $\hat{\sigma}_{i j}$ that remains constant during the cycle.

The second property is that the yield stress values at $t_{1}$ and $t_{2}$ need not be identical. If $\sigma_{y}^{1}$ and $\sigma_{y}^{2}$ are the yield values so associated, the method outlined above remains unchanged except that equation (7) is replaced by

$$
\sigma_{y}^{1}+\sigma_{y}^{2}=\left(\frac{3}{2}\right) 2 \bar{\mu}^{i} \bar{\varepsilon}\left(\Delta \varepsilon_{i j}^{i}\right)
$$

and, at convergence,

$$
\bar{\sigma}\left(\Delta \hat{\sigma}_{i j}+\Delta \rho_{i j}^{f}\right)=\sigma_{y}^{1}+\sigma_{y}^{2}
$$

\section{Creep Relaxation}

Now consider the history of load and temperature shown in Figure 1. During the time interval $t_{1} \leq t \leq t_{1}+\Delta t$, where $\tau=t-t_{1}$, relaxation of stress takes place so that $\sigma_{i j}(0)=\sigma_{i j}^{c}-\Delta \rho_{i j}^{c}$ and 
$\sigma_{i j}(\Delta t)=\sigma_{i j}^{c}$. A creep strain $\Delta \varepsilon_{i j}^{c}$ occurs, related to the relaxation of stress $\Delta \rho_{i j}^{c}$ by the equations (8) and (9), i.e.

$$
\begin{aligned}
& \Delta \varepsilon_{i j}^{T^{\prime}}=\frac{1}{2 \mu} \Delta \rho_{i j}^{c^{\prime}}+\Delta \varepsilon_{i j}^{c} \\
& \Delta \varepsilon_{k k}^{T c}=\frac{1}{3 K} \Delta \rho_{k k}^{c}
\end{aligned}
$$

In the following we describe a method of relating $\sigma_{i j}(\Delta t)=\sigma_{i j}^{c}, \Delta \rho_{i j}^{c}$ and $\Delta \varepsilon_{i j}^{c}$ by integration along the relaxation path. With this relationship we then interpret $\Delta \varepsilon_{i j}^{c}$ as associated with $\sigma_{i j}(\Delta t)=\sigma_{i j}^{c}$ and arrive at a calculation that is equivalent to the reverse plasticity calculation described above, except that the yield value corresponding to $t=t_{1}+\Delta t, \bar{\sigma}\left(\sigma_{i j}^{c}\right)=\sigma^{c}$ is an implicit function of $\Delta \varepsilon_{i j}^{c}$ and $\Delta \rho_{i j}^{c}$.

\section{Integration of the Relaxation Process}

In conformity with the plasticity solution we assume a kinematically constrained solution where the creep strain rate during $t_{1} \leq t \leq t_{1}+\Delta t$ remains in a constant tensorial direction, i.e. $\dot{\varepsilon}_{i j}^{c}=\overline{\dot{\varepsilon}}^{c} n_{i j}$ where $n_{i j}$ is a constant tensor. The constitutive relation is assumed to be Norton's law,

$$
\dot{\varepsilon}_{i j}^{c}=\frac{3}{2} \frac{\dot{\varepsilon}_{0}}{\sigma_{0}^{n}} \bar{\sigma}^{n-1} \sigma_{i j}^{\prime}, \text { i.e. } \quad \overline{\dot{\varepsilon}}^{c}=\frac{\dot{\varepsilon}_{0}}{\sigma_{0}^{n}} \bar{\sigma}^{n}
$$

where $n$ is the creep index of the material, $\dot{\varepsilon}_{0}$ is the uniaxial steady state creep rate corresponding to temperature $\theta$ and uniaxial stress $\sigma_{0}$. Hence $\sigma_{i j}^{\prime}$ describes a radial path in deviatoric stress space and $\bar{\sigma}\left(\dot{\sigma}_{i j}\right)=\dot{\bar{\sigma}}\left(\sigma_{i j}\right) . \bar{\sigma}$ denotes the von Mises effective stress and $\overline{\dot{\varepsilon}}$ the von Mises 
effective strain. During the relaxation process we assume, at each point in space, that an elastic follow-up factor $\mathrm{Z}$ exists, i.e. for uni-axial conditions

$$
\dot{\varepsilon}^{c}=-\frac{Z}{E} \dot{\sigma} \quad \text { and } \quad \overline{\dot{\varepsilon}}^{c}=-\frac{Z}{\bar{E}} \dot{\bar{\sigma}}
$$

for multi-axial conditions where $\bar{E}=\frac{3 E}{2(1+v)}$.

Combining (16) and (17) and integrating over the relaxation period, we obtain

$$
\frac{\dot{\varepsilon}_{0} \bar{E}}{\sigma_{0}^{n} Z} \Delta t=-\int_{0}^{\Delta \rho^{c}} \frac{d \bar{\sigma}}{\bar{\sigma}^{n}}=\frac{1}{n-1}\left\{\frac{1}{\left(\sigma^{c}\right)^{n-1}}-\frac{1}{\left(\sigma^{c}+\Delta \rho^{c}\right)^{n-1}}\right\}
$$

where $\Delta \rho^{c}=\bar{\sigma}\left(\Delta \rho_{i j}^{c}\right)$. Integrating (17) gives

$$
\bar{\varepsilon}\left(\Delta \varepsilon_{i j}^{c}\right)=\Delta \varepsilon^{c}=\frac{Z}{\bar{E}} \Delta \rho^{c}
$$

Combining (18) and (19) and eliminating $Z / \bar{E}$ provides an implicit relationship between the effective values $\sigma^{c}, \Delta \rho^{c}$ and $\Delta \varepsilon^{c}$. Computationally it is advantageous to be able to compute $\sigma^{c}$ at each iteration in terms of a fictional rate $\overline{\dot{\varepsilon}}^{F}$,

$$
\sigma^{c}=\sigma_{0}\left(\frac{\dot{\dot{\varepsilon}}^{F}}{\dot{\varepsilon}_{0}}\right)^{1 / n}
$$

Combining(18), (19) and (20) gives,

$$
\overline{\dot{\varepsilon}}^{F}=\frac{\Delta \varepsilon^{c}}{\Delta t} f\left(\sigma_{f}, \Delta \rho^{c}, n\right)=\frac{\Delta \varepsilon^{c}}{\Delta t}\left\{\frac{\left(\sigma^{c}\right)^{n}}{\Delta \rho^{c}} \frac{1}{n-1}\left\{\frac{1}{\left(\sigma^{c}\right)^{n-1}}-\frac{1}{\left(\sigma^{c}+\Delta \rho^{c}\right)^{n-1}}\right\}\right\}
$$

Hence in the iterative process we begin with current estimates $\sigma^{c i}, \Delta \rho^{c i}$ and $\Delta \varepsilon^{c i}$ and compute a new value of the creep stress $\sigma^{c}=\sigma^{c f}$ from (20) where

$$
\overline{\dot{\varepsilon}}^{F}=\frac{\Delta \varepsilon^{c i}}{\Delta t} f\left(\sigma^{c i}, \Delta \rho^{c i}, n\right)
$$


Note that in the limit when $\Delta \rho^{c} / \sigma^{c}$ is small, $f \rightarrow 1 \quad$ and

$$
\overline{\dot{\varepsilon}}^{F}=\Delta \varepsilon^{c} / \Delta t
$$

with an error of the order of $\left(\Delta \rho^{c} / \sigma^{c}\right)^{2}$.

On the basis of this calculation we develop two alternative solution schemes.

Method 1: The solution scheme consists of two parts as illustrated in Figure (3B). Initially creep relaxation is ignored and the amplitude of plastic strain $\Delta \varepsilon_{i j}^{p}$ is evaluated by the methods of (Ponter and Chen, 2001; Chen and Ponter, 2001b) as described above. The solution method is then repeated with the yield stress at time $\tau=\Delta t$ being taken as $\sigma^{c}$ using the iterative scheme (20) and (22A). A linear coefficient $\bar{\mu}^{i}$ is defined by

$$
\sigma_{y}+\sigma_{c}=\left(\frac{3}{2}\right) 2 \bar{\mu}^{i} \bar{\varepsilon}\left(\Delta \varepsilon_{i j}^{c^{i}}\right)
$$

where $\sigma_{c}$ is evaluate from (20) and (21) using values from the previous iteration. The same procedure as in equations (8) to (10) is used except that (11) becomes

$$
\Delta \hat{\sigma}_{i j}=\hat{\sigma}_{i j}\left(t_{1}\right)-\hat{\sigma}_{i j}\left(t_{2}\right)+\Delta \rho_{i j}^{p}
$$

where $\Delta \rho_{i j}^{p}$ is the residual stress change due to the plastic strain. The converged solution then has the property

$$
\bar{\sigma}\left(\Delta \hat{\sigma}_{i j}+\Delta \rho_{i j}^{f}\right)=\sigma_{y}+\sigma_{c}
$$

i.e.

$$
\bar{\sigma}\left(\hat{\sigma}_{i j}\left(t_{1}\right)-\hat{\sigma}_{i j}\left(t_{2}\right)+\Delta \rho_{i j}^{p}+\Delta \rho_{i j}^{c}\right)=\sigma_{y}+\sigma_{c}
$$

thereby producing a consistent solution. 
Method 2: In this solution scheme, we adopt the simpler approximation of equation (22B). The creep dwell time $\Delta t$ is divide it into $m$ increments, i.e. $\Delta t=\Delta t_{1}+\Delta t_{2}+\cdots+\Delta t_{m}$, where $\Delta t_{i}$ is a short time period. and, for each increment

$\dot{\varepsilon}^{F}\left(\Delta t_{1}+\Delta t_{2}+\cdots+\Delta t_{i}\right) \approx \frac{\Delta \varepsilon^{c}\left(\Delta t_{1}+\Delta t_{2}+\cdots+\Delta t_{i}\right)-\Delta \varepsilon^{c}\left(\Delta t_{1}+\Delta t_{2}+\cdots+\Delta t_{i-1}\right)}{\Delta t_{i}}$

Hence in the step 1, we calculate the accumulated creep strain $\Delta \varepsilon^{c}\left(\Delta t_{1}\right)$ using equation (22B) directly. In the step $i$, the equation (25) is used to evaluate the accumulated creep strain $\Delta \varepsilon^{c}\left(\Delta t_{1}+\Delta t_{2}+\cdots+\Delta t_{i}\right)$ based on the solution of $\Delta \varepsilon^{c}\left(\Delta t_{1}+\Delta t_{2}+\cdots+\Delta t_{i-1}\right)$ calculated by step $(i-$ $1)$.

In this calculation the value of $\mathrm{Z}$ may change from increment to increment, in contrast to Method 1 where $\mathrm{Z}$ is assumed to remain constant in time.

Methods 1 and 2 assume no overall accumulation of strain due to creep. The following method relaxes this condition and is useful for comparative purposes.

\section{Method 3 - Creep computation based upon the rapid cycle solutions}

Although it is possible to construct complete cycle solutions in particular cases (Boulbibane and Ponter, 2002) the computational effort is significantly greater than the methods described above. There is however a particular case when a complete cyclic solution is easily constructed using the LMM, in the special case when $\rho_{i j}$ in equation (4) is zero; this occurs for creep problems when the cycle time is very short compared with material times, the so called rapid cycle solution (Ponter and Cocks, 1994; Ponter and Engelhardt, 2000). In the following we construct the rapid cycle solution based upon the elastic solution and the reverse plasticity solution, producing a solution of the form, 


$$
\sigma_{i j}^{i n}=\hat{\sigma}_{i j}(t)+\Delta \rho_{i j}^{p}(t)+\bar{\rho}_{i j}
$$

where $\Delta \rho_{i j}^{p}$ is the varying residual stress field associated with the pure reverse plasticity mechanism (Ponter and Chen, 2001; Chen and Ponter, 2001b), and $\bar{\rho}_{i j}$ is the constant residual stress associated with the rapid cycle solution for creep. The estimate of $Z$ and the creep relaxation strain then obtained by carrying out a step by step solution for the initial value problem

$$
\dot{\varepsilon}_{i j}^{c T}=\frac{1}{2 \mu} \dot{\rho}_{i j}^{\prime}+\dot{\varepsilon}_{i j}^{c}, \quad \dot{\varepsilon}_{k k}^{c T}=\frac{1}{3 K} \dot{\rho}_{k k}
$$

and the creep strain rate is given by Norton's law. The initial condition for the calculation is taken as the rapid cycle solution (26) at $t=t_{1}$. This solution is similar in nature to a method recommended in R5 although the initial stress state here is a more accurate estimate of the cyclic solution. Comparisons with full cyclic solutions (Boulbibane and Ponter, 2002) indicate that the method tends to give an over-estimate of $\mathrm{Z}$ when compared with the exact cyclic solution.

For the rapid cycle solution method we adopt the procedure described by (Ponter and Engelhardt, 2000) and the details will not be given here. The constitutive equation is assumed to be the Bailey Orowan model, which tends to overestimate creep recovery effects.

\section{Numerical example: A plate with a central hole and subjected to varying thermal loads}

The geometry of the structure and its finite element mesh are shown in Fig.5, posed as a three dimensional problem. The 20 -node solid isoparametric element with reduced integration is adopted. The ratio between the diameter $D$ of the hole and the length $L$ of the plate is 0.2 and the ratio of the depth of the plate to the length $L$ of the plate is 0.05 .

The plate is subjected to a temperature difference $\Delta \theta$ between the edge of the hole and the edge of the plate. The variation of the temperature with radius $r$ was assumed to be; 


$$
\theta=\theta_{0}+\Delta \theta \ln (5 a / r) / \ln (5)
$$

which gives a simple approximation to the temperature field corresponding to $\theta=\theta_{0}+\Delta \theta$ around the edge of the hole and $\theta=\theta_{0}$ at edge of the plate.

The elastic stress field and the maximum effective value, $\sigma_{t 0}$, at the edge of the holed plate due to the thermal load was calculated by (ABAQUS, 2001), where $\theta_{0}=0, \Delta \theta=500{ }^{\circ} \mathrm{C}$ and a coefficient of thermal expansion of $10^{-5}{ }^{\circ} \mathrm{C}^{-1}$. The yield stress $\sigma_{Y}=360 \mathrm{MPa}$, and the elastic modulus $\mathrm{E}=208 \mathrm{GPa}$ and $v=0.3$.

For the creep material data in equation (16) we adopt $\sigma_{0}=\frac{\sigma_{y}}{2}$ and $\mathrm{n}=5$, and make two alternative assumptions for the uniaxial steady state creep rate $\dot{\varepsilon}_{0}$ as follows:

$$
\dot{\varepsilon}_{0}=2 \times 10^{-6} / \mathrm{hr}
$$

and $\dot{\varepsilon}_{0}=576.53108 \exp \left[\frac{(-19700)}{(\theta+273)}\right] . / \mathrm{hr}$

where, in (29A) we assume creep properties independent of temperature and in (29B) the creep properties depend on temperature, typical of type 316 stainless steel.

Figure 6 shows the shakedown and ratchet boundaries for the problem, using the methods described in (Ponter and Chen, 2001; Chen and Ponter, 2001b). Note that $\sigma_{t 0}=2 \sigma_{y}$ is the value of $\sigma_{t}$ at the reverse plasticity shakedown limit. In this paper we use the perfect plasticity material model.

Two load cases are shown in Table 2. For load case 1, the applied load domain is beyond the elastic shakedown region and the reverse plasticity mechanism appears adjacent to the hole. The maximum effective amplitude of plastic strain $\Delta \varepsilon^{p}$ for this case is $2.869 \times 10^{-3}$, and the total 
varying strain $\Delta \varepsilon^{r p}$, including creep relaxation is the summation of varying plastic strain $\Delta \varepsilon^{p}$ and accumulated creep strain $\Delta \varepsilon^{c}$. Fig. 7, 8 and 9 present the calculated maximum von Mises creep flow stress, the maximum von Mises creep strain and the elastic follow-up factor $\mathrm{Z}$ with creep dwell time for equation (29A) and (29B), respectively. Although the rate of relaxation and the growth of strain differ, the $Z$ values are very similar, Figures $9 a$ and $9 b$, with lower values for the temperature dependent case. Solutions for Method 1 and 2 are coincident, indicating that the assumption in Method 1, that $\mathrm{Z}$ remains constant during the relaxation process, is acceptable. The results from Method 3 also have a good agreement with those from Method 1 and 2. This numerical fact verifies the applicability of the proposed creep-reverse plasticity solution methods 1 and 2 in the paper as well as the monotonic creep computation method 3 based upon rapid cycle creep solutions.

For load case 2, the applied load domain is in the elastic shakedown region, where $\Delta \varepsilon^{p}=0, \Delta \rho^{p}=0$, and the total varying strain $\Delta \varepsilon^{r p}$ equals to the accumulated creep strain $\Delta \varepsilon^{c}$ induced by creep relaxation. Fig.10, 11 and 12 present the computed maximum von Mises creep flow stress, the maximum von Mises creep strain and the elastic follow-up factor $Z$ with creep dwell time for equation (29A) and equation (29B), respectively. As both the stress levels and maximum temperature is much lower in this case, there is a very marked difference in creep strain growth between Fig $11 \mathrm{a}$ and $11 \mathrm{~b}$. However, the values of $\mathrm{Z}$ in Fig 12a and $12 \mathrm{~b}$ are very similar, where the time scales in each case correspond to similar degree of stress relaxation, as shown in Fig 10a and 10b. For load case 2, the solution for Method 3 tends to give higher values of creep flow stress and strain, although, the $Z$ values are close to those of Method 1 and 2. For all solutions, Method 1 and 2 give near identical values. This indicates that Method 1 , the numerically most efficient of the methods, is acceptable. 


\section{Discussions}

Although the solutions for method 1 and 2 are near identical, they differ from those of method 3 that tends to give higher values of $Z$, particular in the case of loading below the shakedown limit. (Boulbibane and Ponter, 2002) have noted that this method tends to give conservative values of $\mathrm{Z}$ although for a different constitutive equation and loading history.

Methods 1 and 2 use different material assumptions to method 3. In method 3 the BaileyOrowan model is used for the rapid cycle solution. The Bailey-Orowan model produces a different start-of-dwell stress below the shakedown limit, but a value that is very similar to Methods 1 and 2 in excess of shakedown where the initial stress needs to satisfy yield in all cases. If the applied load domain exceeds elastic shakedown and is in the reverse plasticity region, the start-of-dwell stress using rapid cycle solutions by Bailey-Orowan model (method 3 ) is consistent with the initial flow stress by the proposed methods 1 and 2 because in all cases the initial elastic stresses associated with the applied cyclic loads were amended by a varying residual stress field associated with the reverse plasticity mechanism. Both the maximum start-of-dwell stress and initial maximum flow stress equal to the yield stress of the material. Hence for load case 1 in this paper, where the applied load domain induces the reverse plasticity mechanism, the creep-reverse plasticity solution methods 1 and 2 nearly produce the same results as the monotonic creep computation method 3 .

If the applied load domain is below the elastic shakedown limit, the rapid cycle solutions by the Bailey-Orowan model (Boulbibane and Ponter, 2002) produces a start-of-dwell stress that differs from the initial creep flow stress by methods 1 and 2, which is verified by the numerical results for load case 2. The Bailey-Orowan theory gives more conservative estimates of creep strains than the proposed creep-reverse plasticity solution methods in the paper. 
The elastic follow-up factor $\mathrm{Z}$ is assumed reasonably to be a constant when the creep relaxation is dominated by the thermal stress. The further investigations to the effects of the dominant mechanical stress on the creep will be performed in the future paper.

In order to simplify the formulations, the Norton's law is adopted in equation (16) of the paper. Normally, the adoption of Norton's law for creep may cause misevaluation of creep damage during dwell time due to the neglect of transient creep. In order to overcome this, in the paper, we have considered the transient creep by fitting the transient creep data into the Norton's law, i.e. the creep material data in the Norton's law (29B) have already considered the effect of the transient creep, which are different with those for the steady state creep.

Only two load instances are considered in this paper for method 1 and 2, although in method 3 multi-load extremes are adopted. For a general case of arbitrary loading, a more complicated method is being developed and will be presented in the future paper.

\section{Conclusions}

The paper presents three simplified methods for evaluating the creep strains produced during a creep dwell period using various adaptations of the linear matching method. Methods 1 and 2 are derived by adapting an existing (Ponter and Chen, 2001; Chen and Ponter, 2001b) method for the evaluation of the plastic strain amplitude where, in method 1 we assume that relaxation takes place with a constant elastic follow-up factor and there is no growth of total strain over the cycle. Solution 2 retains the zero growth assumption but does not assume a constant value of $Z$. Method 3 allows for overall growth of strain and gives a different initial stress to that of Methods 1 and 2 . Two creep models are used, assuming temperature independent and temperature dependent material data. The primary conclusion from the numerical example is that the value of $\mathrm{Z}$ hardly varies between the three methods and the two creep data, indication that $\mathrm{Z}$ is not particularly 
sensitive to the assumptions made in these particular calculations. The overall implication is that the particular assumptions made in Method 1 are probably acceptable for a general purpose technique for the evaluation of creep/ fatigue interaction. These methods were devised with the needs of the life assessment method R5 particularly in mind, although the approach to creep/fatigue interaction is similar in other life assessment procedures.

The completion of Method 1 involves two stages. The first stage involves the evaluation of the plastic strain amplitude, assuming no creep occurs during the dwell period. This involves the solution of a sequence of linear problems to convergence. The number of iterations required varies with the convergence criterion, but the order of thirty iterations is usually sufficient. If the load level is below the shakedown limit this stage becomes unnecessary. Although the solutions in this paper assume perfect plasticity, cyclic hardening may be included without any increase in the computational effort. The second stage involves a calculation which is computationally similar to the first stage and the same effort is required. Hence a complete solution for a particular case would require the solution of about sixty linear initial strain problems.

This study provides a first attempt to produce efficient methods for creep/fatigue interaction using the Linear Matching method where the calculation is specific to the circumstance of the problem and where reliance is placed on elementary material data rather than a full constitutive relationship. There are clearly ways in which these calculations may be developed, for more complex histories of loading and where the material data is provided by a constitutive relationship. These must await further study. 


\section{Appendix 1: Elastic Follow-up factor $Z$ for proportional relaxation}

Consider the case when a structure with volume $\mathrm{V}$ possesses a residual stress field $\sigma_{i j}^{0}$ at time $t=0$. For $t>0$, creep occurs where the total strain rate $\dot{\varepsilon}_{i j}$ is given by,

$$
\begin{aligned}
& \dot{\varepsilon}_{i j}^{\prime}=\frac{1}{2 \mu} \dot{\sigma}_{i j}^{\prime}+\frac{\dot{\varepsilon}_{0}}{\sigma_{0}^{n}} \bar{\sigma}^{n-1} \frac{3}{2} \sigma_{i j}^{\prime} G\left(T, T_{0}\right) \\
& \dot{\varepsilon}_{k k}=\frac{1}{K} \dot{\sigma}_{k k} \\
& G\left(T, T_{0}\right)=\exp -\frac{Q}{R}\left\{\frac{1}{T}-\frac{1}{T_{0}}\right\}
\end{aligned}
$$

where $\dot{\varepsilon}_{0}$ denotes the uniaxial creep rate corresponding to an uniaxial stress $\sigma_{0}$ at a temperature $T_{0}$. The creep behaviour is governed by the creep index $n$ and the creep activation energy $Q$. $R$ denotes the universal gas constant and $(\mu, K)$ denote the linear elastic shear and bulk moduli, assumed temperature independent. Consider a history of stress relaxation for $t>0$,

$$
\sigma_{i j}(t)=\sigma_{i j}^{0} f(t)
$$

As $\sigma_{i j}^{0}$ is a residual stress field,

$$
\int_{V} \sigma_{i j}^{0} \dot{\varepsilon}_{i j}=0
$$

and hence, from A1.1 and A1.2,

$$
0=2 U \dot{f}(t)+\dot{D}^{C} f^{n}(t)
$$

where $U$ denotes the total elastic complementary strain energy at $t=0$,

$$
U=\frac{1}{2} \int_{V}\left\{\frac{1}{2 \mu} \sigma_{i j}^{0^{\prime}} \sigma_{i j}^{0^{\prime}}+\frac{1}{K} \sigma_{k k}^{0^{2}}\right\} d V
$$

and $\dot{D}^{C}$ denotes the total creep energy dissipation rate, 


$$
\dot{D}^{C}=\int_{V} \frac{\dot{\varepsilon}_{0}}{\sigma_{0}^{n}} \bar{\sigma}^{n+1}\left(\sigma_{i j}^{0}\right) G d V
$$

Integrating equation (A1.5) we obtain, assuming $n>1$,

$$
f(t)=\frac{1}{(1+(n-1) \alpha t)^{\frac{1}{(n-1)}}} \quad \text { where } \alpha=\frac{\dot{D}^{C}}{U}
$$

With $f(t)$ known, the elastic follow-up factor may be computed for any position in the structure.

From A1.3 and A1.1,

$$
\bar{\sigma}(t)=\bar{\sigma}^{0} f(t), \bar{\varepsilon}^{C}(t)=\frac{\dot{\varepsilon}_{0}}{\sigma_{0}^{n}} \bar{\sigma}^{0} \int_{0}^{t} f^{n} d t
$$

where $\bar{\sigma}^{o}$ denotes the effective stress at $t=0$ and $\bar{\varepsilon}^{C}$ the effective creep strain accumulated since $t=0$. The effective Young's modulus during stress relation is, therefore given by,

$$
\frac{3 E_{e f f}}{2(1+v)}=\frac{3 E}{2(1+v)} \frac{1}{Z}=\frac{\left(\bar{\sigma}^{0}-\bar{\sigma}^{0} f(t)\right)}{\bar{\varepsilon}^{C}}=\alpha \frac{\sigma_{0}^{n}}{\dot{\varepsilon}_{0} \bar{\sigma}_{0}^{n-1}}
$$

The maximum value of $\mathrm{Z}$ generally occurs in the location where $\bar{\sigma}_{0}=\bar{\sigma}_{0}^{\max }$ at the position of maximum effective stress at $t=0$. We will assume that $T=T_{0}$ at the same location and adjust $\dot{\varepsilon}_{0}$ accordingly. From A1.6, A1.7 and A1.8, A1.10 may now be expressed in the following form;

$$
Z=\frac{2 \widetilde{U}}{\tilde{\dot{D}}^{c}}
$$

where $\widetilde{\dot{D}}^{C}$ and $\widetilde{U}$ are the creep energy dissipation and complementary elastic strain energy normalised with respect to the maximum effective stress $\bar{\sigma}_{0}^{\max }$,

$$
\widetilde{\dot{D}}^{C}=\int_{V}\left\{\frac{\bar{\sigma}\left(\sigma_{i j}^{0}\right)}{\bar{\sigma}_{0}^{\max }}\right\}^{n+1} G d V
$$

and 


$$
\widetilde{U}=\frac{1}{2} \int_{V} \frac{\left\{\frac{1}{2 \mu} \sigma_{i j}^{0^{\prime}} \sigma_{i j}^{0^{\prime}}+\frac{1}{K} \sigma_{k k}^{0^{2}}\right\}}{\frac{2(1+v)}{3 E}\left(\bar{\sigma}_{0}^{\max }\right)^{2}} d V
$$

Equations A1.11, A1.12 and A1.13, provide valuable insight into the dependence of $\mathrm{Z}$ on the characteristics of the problem.

a) $\quad \mathrm{Z}$ is independent of the overall magnitude of the stress distribution, i.e. the stress distribution $\sigma_{i j}^{0}$ and $X \sigma_{i j}^{0}$, where $X$ is a constant, will give identical values of $Z$. However $\mathrm{Z}$ is strongly dependent on the distribution of the stress.

b) Z is independent of Young's modulus $E$, but weakly dependent on Poisson's ratio $v$.

c) $\mathrm{Z}$ is independent of the overall creep rate, but dependent on the creep index $n$, the distribution of G.

\section{Appendix 2: $\mathrm{Z}$ for beam problems}

For a mean subjected to loads perpendicular to it's length, a similar analysis may be carried out when the total curviture rate

$$
\dot{\kappa}=\frac{\dot{M}}{E I}+\frac{\dot{\kappa}_{0}}{M_{0}^{n}} M^{n} G\left(T, T_{0}\right)
$$

where $\dot{\kappa}_{0}$ is the curvature rate occurring at temperature $T_{0}$ and moment $M_{0}$. Again, for a moment history of the form $M(x, t)=M_{0}(x) f(t)$, the elastic follow-up factor $\mathrm{Z}$ is given by,

$$
Z=\frac{2 \widetilde{U}}{\widetilde{\dot{D}}^{c}}
$$

where 


$$
\tilde{\dot{D}}=\int_{0}^{l}\left\{\frac{M_{0}}{M_{0}^{\max }}\right\}^{n+1} G d x
$$

and

$$
\widetilde{U}=\frac{1}{2} \int_{0}^{l}\left\{\frac{M_{o}}{M_{0}^{\max }}\right\}^{2} d x
$$

Consider the following special cases,

Case 1: Cantilever beam of length $\mathrm{L}$, subjected to a fixed lateral end displacement and uniform temperature (Figure A1).

$$
M(x, t)=M_{\max }\left(1-\frac{x}{L}\right) f(t)
$$

where $M_{\max }=M(0,0)$.

$$
Z=\frac{\int_{0}^{L}\left(1-\frac{x}{L}\right)^{2} d x}{\int_{0}^{L}\left(1-\frac{x}{L}\right)^{n+1} d x}=\frac{n+2}{3}
$$

Case 2: Cantilever beam of length $\mathrm{L}$, subjected to a fixed lateral end displacement and uniform temperature in $0 \leq x \leq \beta L$ where $G=1$. In $\beta L \leq x \leq L, G=0$.(Figure A1)

$$
Z=\frac{\int_{0}^{L}\left(1-\frac{x}{L}\right)^{2} d x}{\int_{0}^{\beta L}\left(1-\frac{x}{L}\right)^{n+1} d x}=\frac{n+2}{3\left(1-(1-\beta)^{n+2}\right)}
$$

Case 3 and 4: Beam of length $(2 \alpha+1) L$ under four point bending and uniform temperature (Figure A2). 
At $t=0$ displacements are assigned at the four loading points so that the moment in the central section is constant. These displacements are then held constant. For Case 3 we assume that $\mathrm{G}=1$ for the entire beam giving,

$$
Z=\frac{3(2 \alpha+2+n)}{(2 \alpha+3)(n+2)}
$$

If we now assume, Case 4, that creep occurs only in the central section and no creep occurs in the outer sections,

$$
Z=\left(\frac{2 \alpha}{3}+1\right)
$$

and $\mathrm{Z}$ is independent of $\mathrm{n}$.

\section{Acknowledgements}

The authors gratefully acknowledge the support of the Engineering and Physical Sciences Research Council of the United Kingdom, British Energy Ltd and the University of the Leicester during the course of this work.

\section{References}

ABAQUS, 2001. User's Manual, Version 6.2.

Ainsworth, R.A. (editor), 2003. R5: Assessment Procedure for the High Temperature Response of Structures. Issue 3, British Energy Generation Ltd.

Ainsworth, R.A., Budden, P.J., 1992. Approximate inelastic analysis of defective components. Nuclear Engineering and Design 133, 513-523. 
Boulbibane, M., Ponter, A. R. S., 2002. A Method for the Evaluation of Design Limits for Structural Materials in a Cyclic State of Creep. European Journal of Mechanics, A/Solids, 21 (6), 899-914.

Boyle, J.T., Hamilton, R., Shi, J., Mackenzie, D., 1997. Simple method of calculating lowerbound limit loads for axisymmetric thin shells. Journal of Pressure Vessel Tech 119, 236-242.

Chen, H. F., Engelhardt, M.J., Ponter, A.R.S., 2003. Linear matching method for creep rupture assessment. International Journal of Pressure Vessels and Piping, Vol. 80, 213-220.

Chen, H. F., Liu, Y. H., Cen, Z. Z., Xu, B. Y., 1999. On the Solution of Limit Load and Reference Stress of 3-D Structures under Multi-loading Systems. Engineering Structures, Vol. 21, 530537.

Chen, H. F., Ponter, A.R.S., 2001a. Shakedown and Limit Analyses for 3-D Structures Using the Linear Matching Method. International Journal of Pressure Vessels and Piping, Vol. 78(6), $443-451$

Chen, H. F., Ponter, A.R.S., 2001b. A Method for the Evaluation of a Ratchet Limit and the Amplitude of Plastic Strain for Bodies Subjected to Cyclic Loading. European Journal of Mechanics, A/Solids, 20 (4), 555-571.

Corradi, L., Zavelani, A., 1974. A linear programming approach to shakedown analysis of structures. Comput. Methods Appl. Mech. Engrg., Vol. 3, 37-53.

Engelhardt, M., 1999. Computational modelling of Shakedown. PhD thesis, University of Leicester.

Hachemi, A., Weichert, D., 1998. Numerical shakedown analysis of damaged structures. Comput. Methods Appl. Mech. Engrg., Vol. 160, 57-70. 
Hubel, H., Zeibig, H., 1996. State of the art of simplified methods to account for elastic follow-up in creep. EUR 16556EN, Directorate-General Science, Research and Development, Office of Official Publication of the European Communities, ISBN 92-827-5009-4.

Mackenzie, D., Boyle, J. T., Hamilton, R., Shi, J., 1996. Elastic compensation method in shellbased design by analysis. Proceedings of the 1996 ASME Pressure Vessels and Piping Conference, Vol. 338, 203-208.

Maier, G., 1977. Mathematical programming methods for deformation analysis at plastic collapse. Computers and Structures, Vol. 7, 599-612.

Ponter, A.R.S., Chen, H. F., 2001. A minimum theorem for cyclic load in excess of shakedown, with application to the evaluation of a ratchet limit. European Journal of Mechanics, A/Solids, $20(4), 539-553$

Ponter, A.R.S., Cocks, A.C.F., 1994. Computation of shakedown limits for structural components (Brussels Diagram)-Part 2-The creep range. Nuclear Science and Technology, European Commission, Report No. EUR 15682EN, Luxembourg.

Ponter, A. R. S., Engelhardt, M., 2000. Shakedown limits for a general yield condition: implementation and application for a Von Mises yield condition. European Journal of Mechanics - A/Solids, Volume 19, Issue 3, 423-445.

Seshadri, R., Mangalaramanan, S. P., 1998. Lower bound limit loads of cracked and notched components using reduced modulus methods. Proceedings of the 1998 ASME/JSME joint Pressure Vessels and Piping Conf, Vol. 368, 129-138. 


\section{Caption}

Table 1. Variation of the Elastic Follow-up factor $\mathrm{Z}$ with creep index $\mathrm{n}$ for the beam problems of Figure A1 and A2

Table 2. The definition of load domains for the holed plate

Fig. 1 The load history with two distinct extremes to the elastic solution

Fig. 2 Creep-reverse plasticity mechanisms by steady cyclic loads

Fig. 3 Schematic representation of the quantities for (a) pure reverse plasticity mechanism and (b) creep-reverse plasticity mechanism

Fig. 4 The flow chart for creep-reverse plasticity solution method

Fig. 5 The geometry of the holed plate subjected to varying thermal loads and its finite element mesh $(\mathrm{D} / \mathrm{L}=0.2)$, the yield stress $\sigma_{Y}=360 M P a$, the elastic modulus $E=208 G P a$

Fig. 6 The elastic, shakedown, reverse plasticity and ratchet region for the holed plate with constant mechanical and varying thermal loading

Fig. 7 The maximum flow stress with creep dwell time for a holed plate subjected to varying thermal loads from 0 to $1.5 \sigma_{t 0}$ (a)with constant $\dot{\varepsilon}_{0}$ using eqn (27A); (b) with temperature-dependent $\dot{\varepsilon}_{0}$ using eqn (27B)

Fig. 8 The maximum creep strain with creep dwell time for a holed plate subjected to varying thermal loads from 0 to $1.5 \sigma_{t 0}$ (a)with constant $\dot{\varepsilon}_{0}$ using eqn (27A); (b) with temperature-dependent $\dot{\varepsilon}_{0}$ using eqn (27B) 
Fig. 9 The elastic follow-up factor $\mathrm{Z}$ with creep dwell time for a holed plate subjected to varying thermal loads from 0 to $1.5 \sigma_{t 0}$ (a) with constant $\dot{\varepsilon}_{0}$ using eqn $(27 \mathrm{~A})$; (b) with temperature-dependent $\dot{\varepsilon}_{0}$ using eqn (27B)

Fig. 10 The maximum flow stress with creep dwell time for a holed plate subjected to varying thermal loads from 0 to $0.8 \sigma_{t 0}$ (a) with constant $\dot{\varepsilon}_{0}$ using eqn (27A); (b) with temperature-dependent $\dot{\varepsilon}_{0}$ using eqn (27B)

Fig. 11 The maximum creep strain with creep dwell time for a holed plate subjected to varying thermal loads from 0 to $0.8 \sigma_{t 0}$ (a) with constant $\dot{\varepsilon}_{0}$ using eqn (27A); (b) with temperature-dependent $\dot{\varepsilon}_{0}$ using eqn (27B)

Fig. 12 The elastic follow-up factor $Z$ with creep dwell time for a holed plate subjected to varying thermal loads from 0 to $0.8 \sigma_{t 0}$ (a) with constant $\dot{\varepsilon}_{0}$ using eqn (27A); (b) with temperature-dependent $\dot{\varepsilon}_{0}$ using eqn (27B)

Fig. A1 Configuration for Case 1 and 2

Fig. A2 Beam under four point bending, Cases 3 and 4 
Table 1 Variation of the Elastic Follow-up factor $\mathbf{Z}$ with creep index $\mathbf{n}$ for the beam

\section{problems of Figure A1 and A2}

Case 1 - Propped cantilever, creep over entire length

Case $2 \mathrm{a}$ - Propped cantilever, creep over 0.5 of length

Case $2 b$ - Propped cantilever, creep over 0.1 of length

Case 3- Beam under four point bending, creep over entire length

Case 4 - Beam under four point bending, creep over constant moment section

\begin{tabular}{|c|c|c|c|c|c|}
\hline $\mathrm{n}$ & 1 & 3 & 5 & 7 & $n \rightarrow \infty$ \\
\hline Case 1 & 1 & 1.67 & 2.33 & 3.00 & $\infty$ \\
\hline Case $2 \mathrm{a}, \beta=0.5$ & 1.14 & 1.72 & 2.33 & 3.01 & $\infty$ \\
\hline Case $2 \mathrm{~b}, \beta=0.1$ & 3.69 & 4.07 & 4.47 & 4.90 & $\infty$ \\
\hline Case $3, \alpha=1$ & 1 & 1.19 & 1.30 & 1.36 & 1.67 \\
\hline Case $4, \alpha=1$ & 1.67 & 1.67 & 1.67 & 1.67 & 1.67 \\
\hline
\end{tabular}

Table 2 The definition of load domains for the holed plate

\begin{tabular}{|c|c|c|c|}
\hline Case & The cyclic thermal load $\Delta \theta$ & $\Delta \varepsilon^{p}$ & $\Delta \varepsilon^{r p}$ \\
\hline Case 1 & $1.5 \sigma_{t 0} \rightarrow 0 \rightarrow 1.5 \sigma_{t 0} \rightarrow 0 \rightarrow 1.5 \sigma_{t 0} \cdots$ & $2.869 \times 10^{-3}$ & $\Delta \varepsilon^{p}+\Delta \varepsilon^{c}(t)$ \\
\hline Case 2 & $0.8 \sigma_{t 0} \rightarrow 0 \rightarrow 0.8 \sigma_{t 0} \rightarrow 0 \rightarrow 0.8 \sigma_{t 0} \cdots$ & $\mathbf{0}$ & $\Delta \varepsilon^{c}(t)$ \\
\hline
\end{tabular}



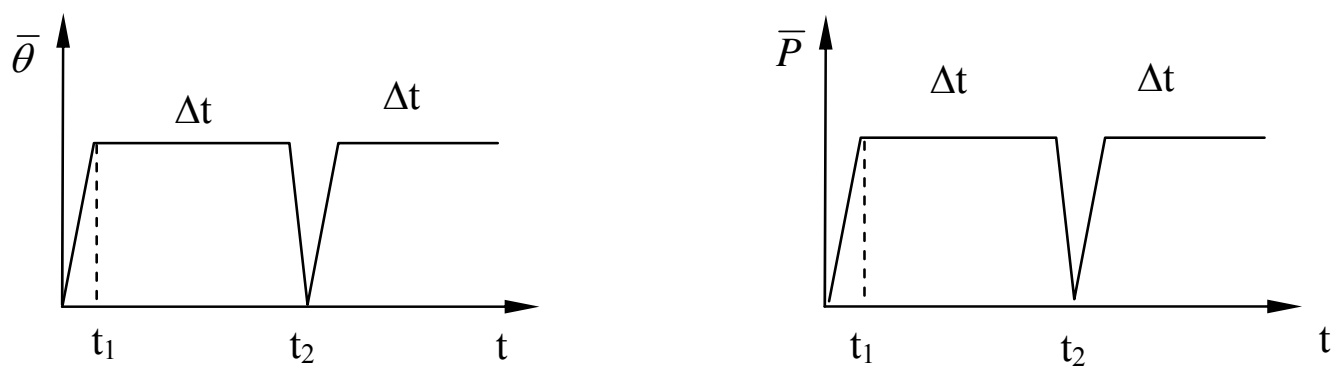

Fig. 1 The load history with two distinct extremes to the elastic solution

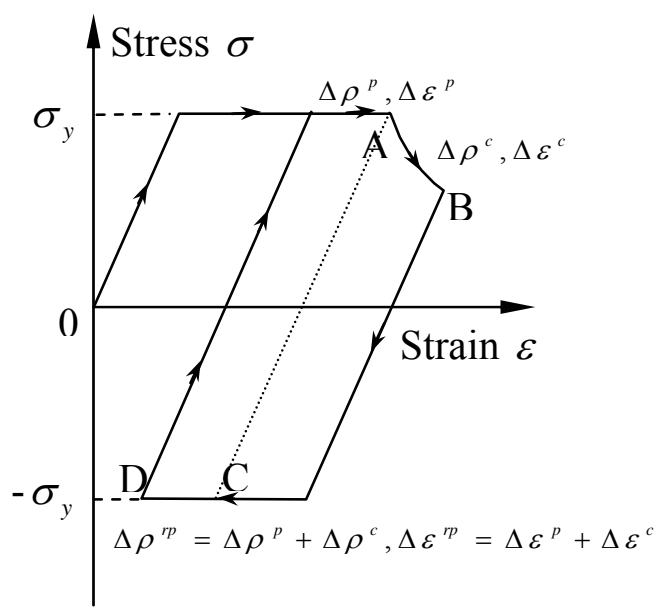

(a) $\Delta \rho^{p} \neq 0, \Delta \varepsilon^{p} \neq 0$

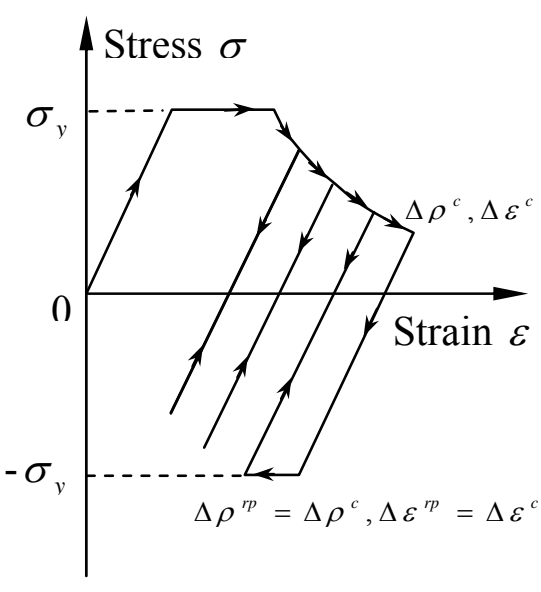

(b) $\Delta \rho^{p}=0, \Delta \varepsilon^{p}=0$

Fig. 2 Creep-reverse plasticity mechanisms by steady cyclic loads

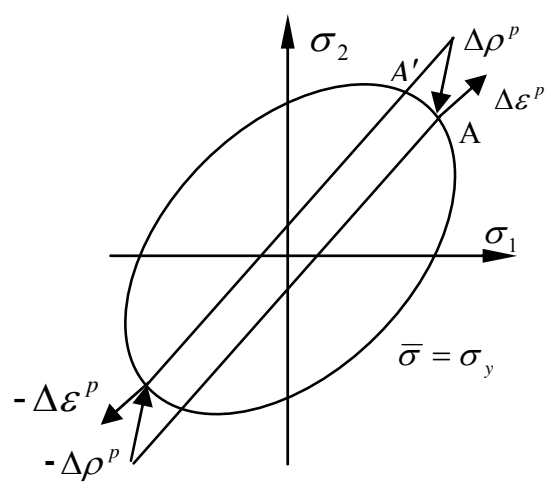

(a)

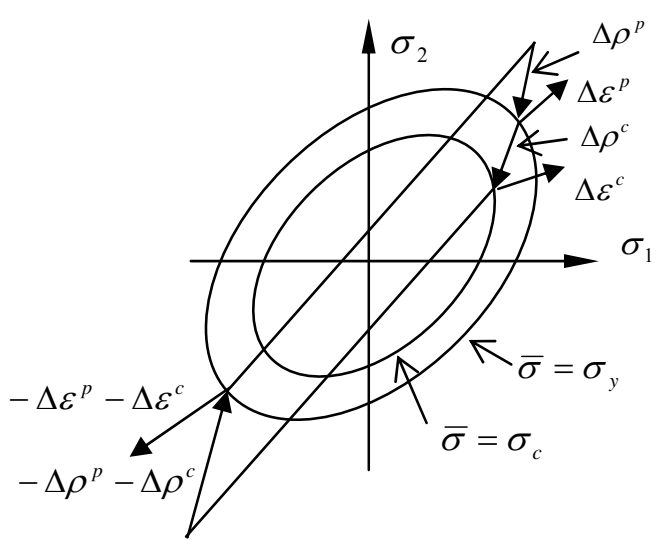

(b)

Fig. 3 Schematic representation of the quantities for (a) pure reverse plasticity mechanism and (b) creep-reverse plasticity mechanism 


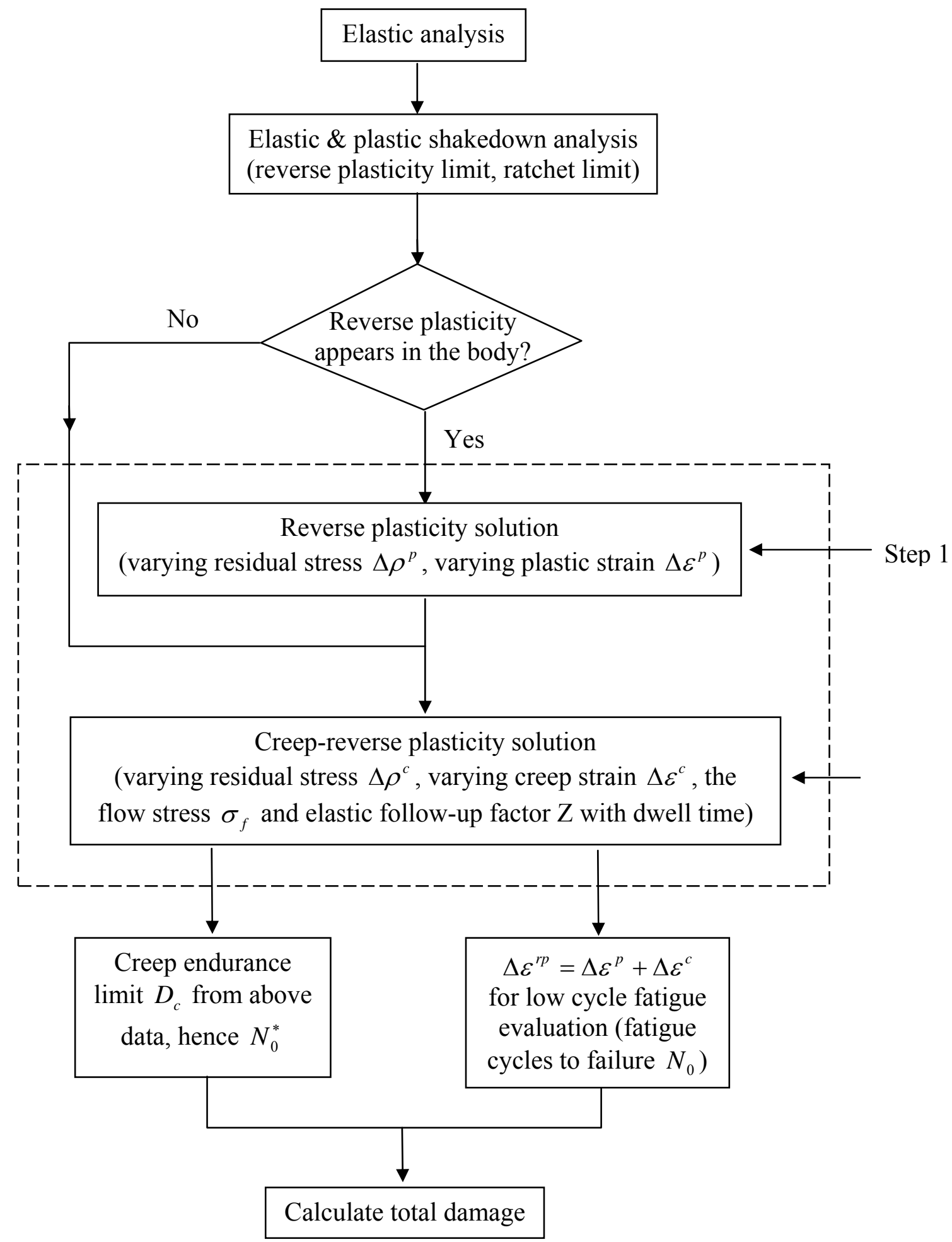

Fig. 4 The flow chart for creep-reverse plasticity solution method 

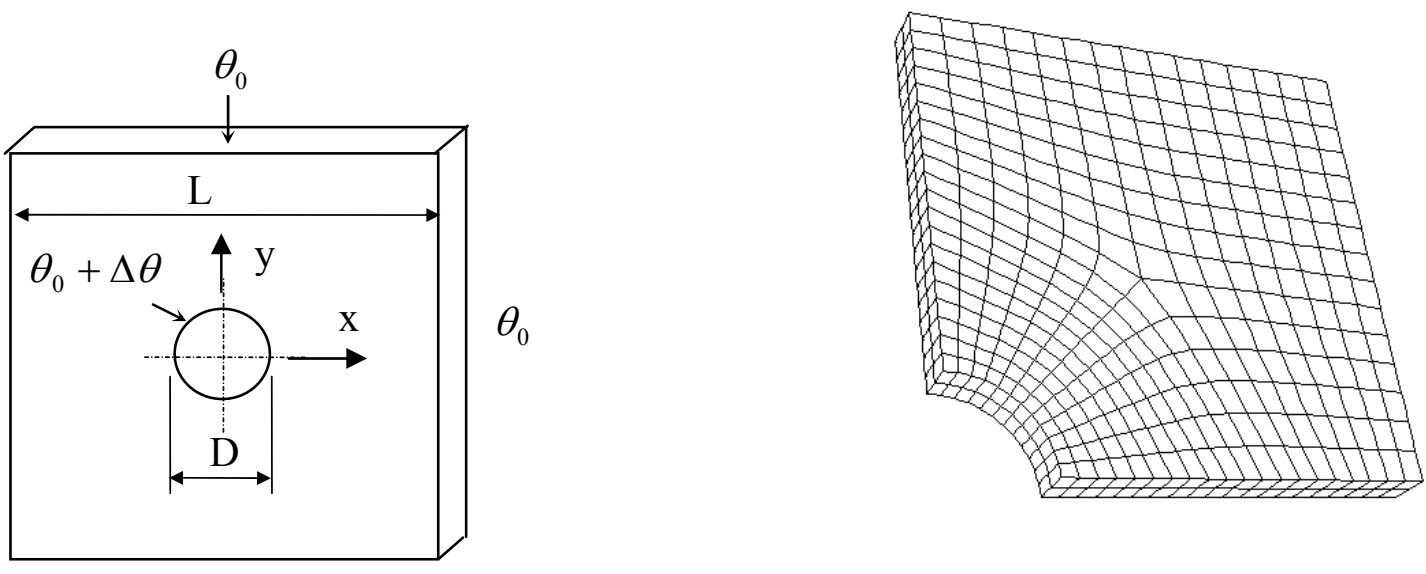

Fig. 5 The geometry of the holed plate subjected to varying thermal loads and its finite element mesh $(\mathrm{D} / \mathrm{L}=\mathbf{0 . 2})$, the yield stress $\sigma_{Y}=360 \mathrm{MPa}$, the elastic modulus $E=208 G P a$

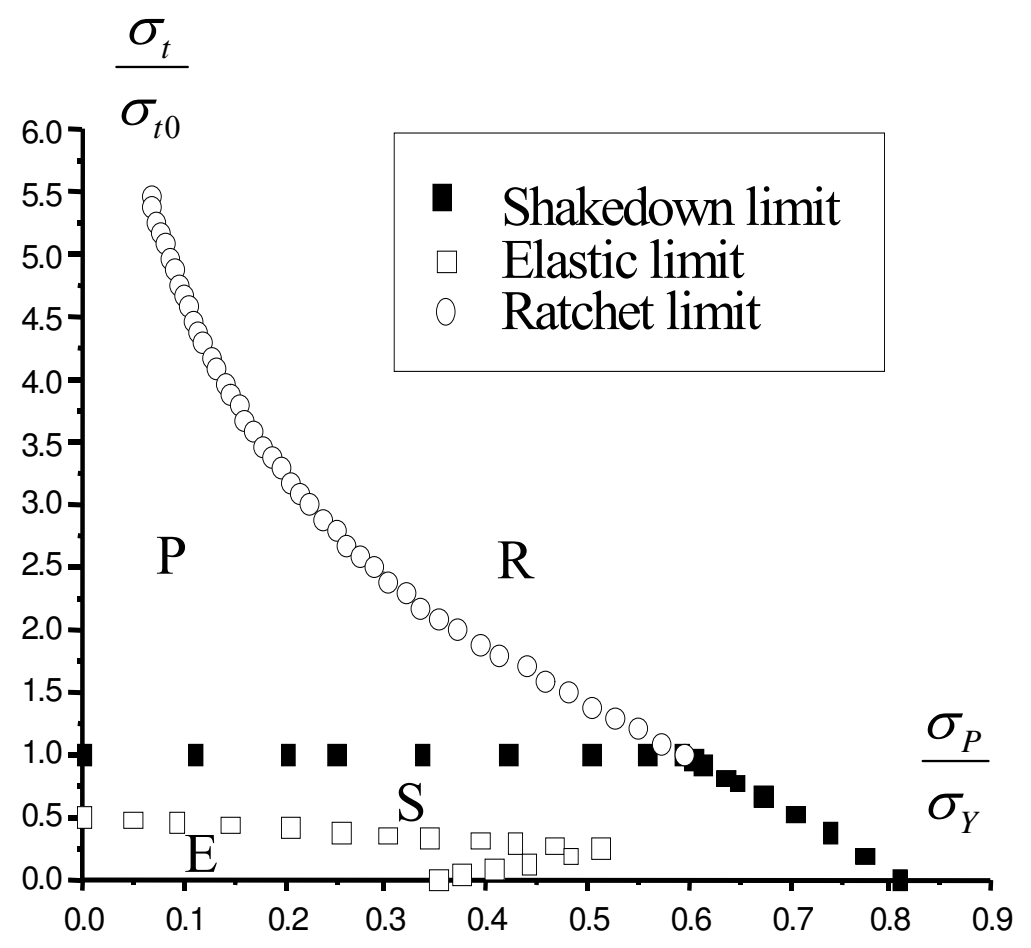

Fig. 6 The elastic, shakedown, reverse plasticity and ratchet region for the holed plate with constant mechanical and varying thermal loading 


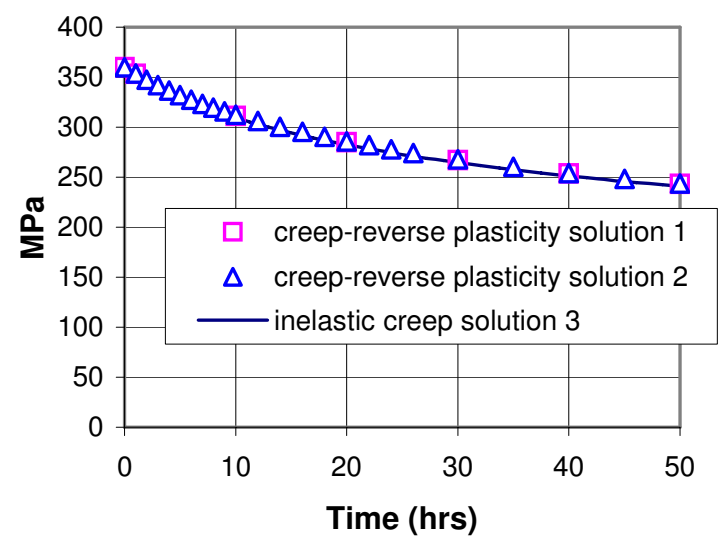

(a)

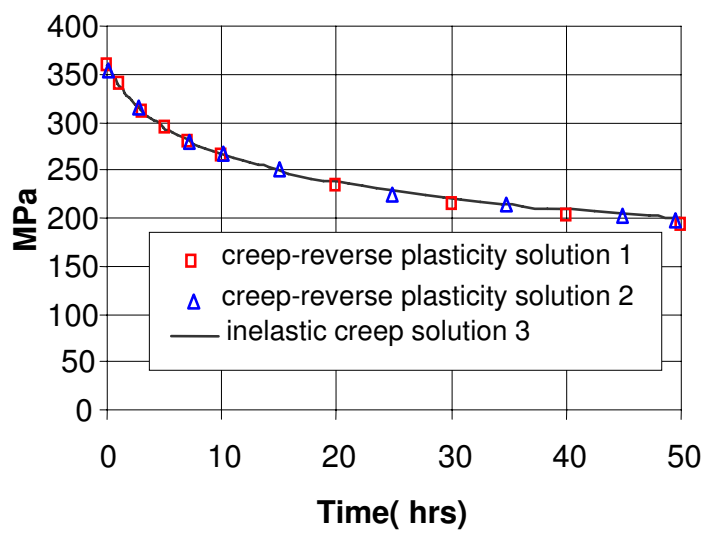

(b)

Fig. 7 The maximum flow stress with creep dwell time for a holed plate subjected to varying thermal loads from 0 to $1.5 \sigma_{t 0}$ (a) with constant $\dot{\varepsilon}_{0}$ using eqn (27A); (b)with temperature-dependent $\dot{\varepsilon}_{0}$ using eqn (27B)

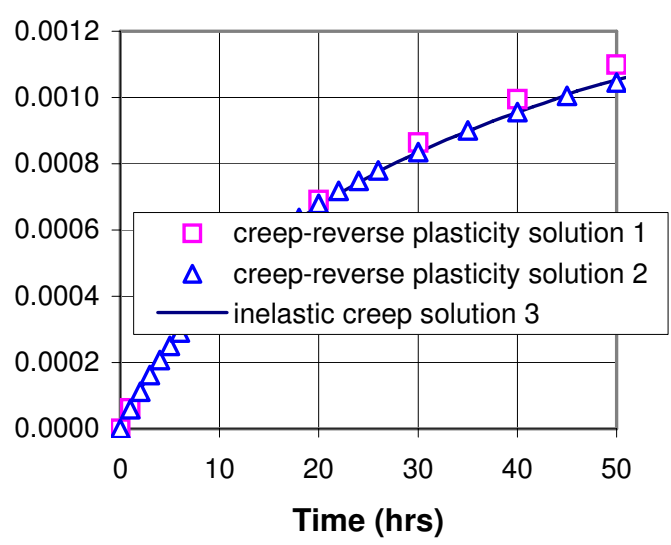

(a)

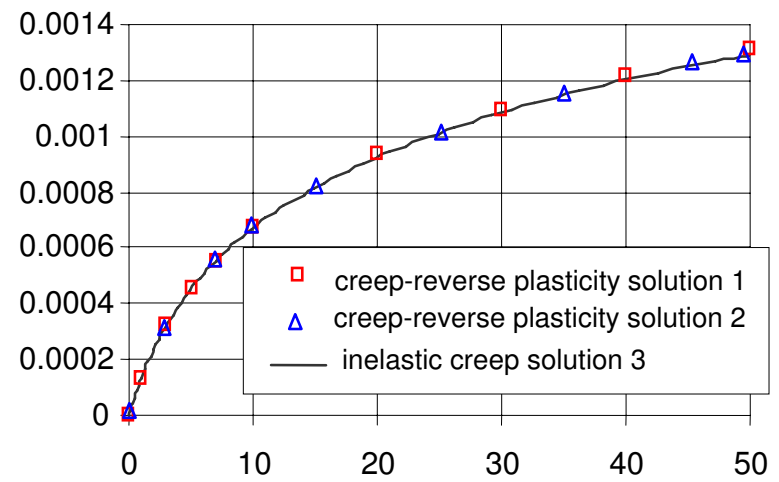

(b)

Fig. 8 The maximum creep strain with creep dwell time for a holed plate subjected to varying thermal loads from 0 to $1.5 \sigma_{t 0}$ (a) with constant $\dot{\varepsilon}_{0}$ using eqn (27A); (b) with temperature-dependent $\dot{\varepsilon}_{0}$ using eqn (27B) 


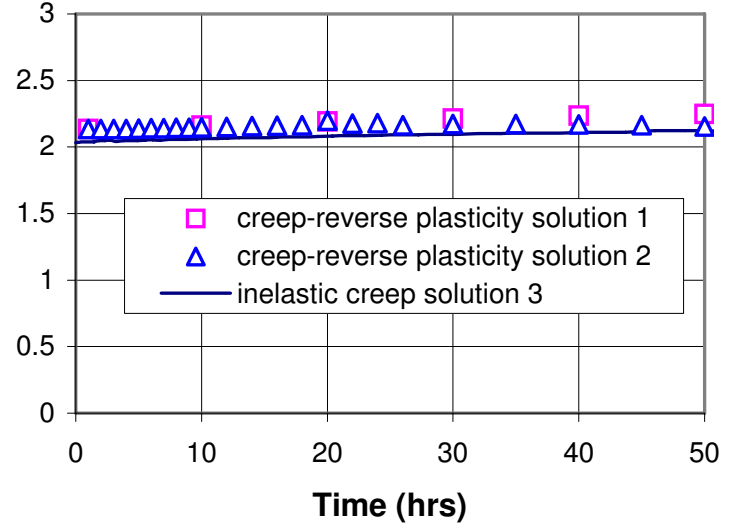

(a)

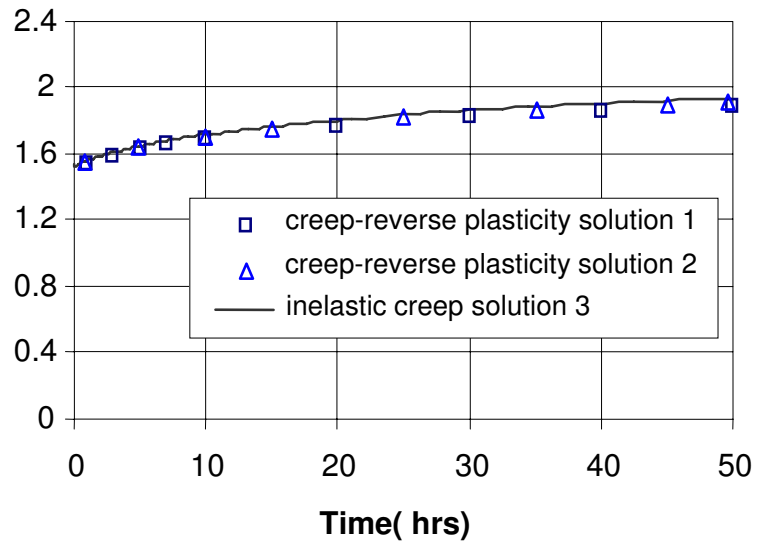

(b)

Fig. 9 The elastic follow-up factor $Z$ with creep dwell time for a holed plate subjected to varying thermal loads from 0 to $1.5 \sigma_{t 0}$ (a) with constant $\dot{\varepsilon}_{0}$ using eqn (27A); (b) with temperature-dependent $\dot{\varepsilon}_{0}$ using eqn (27B)

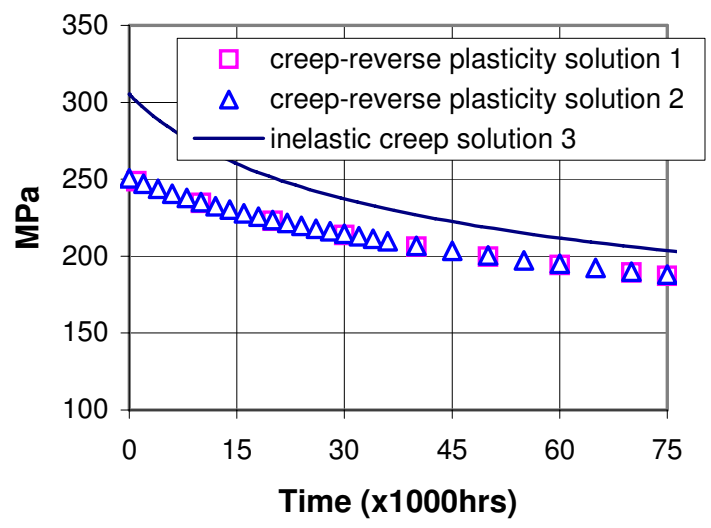

(a)

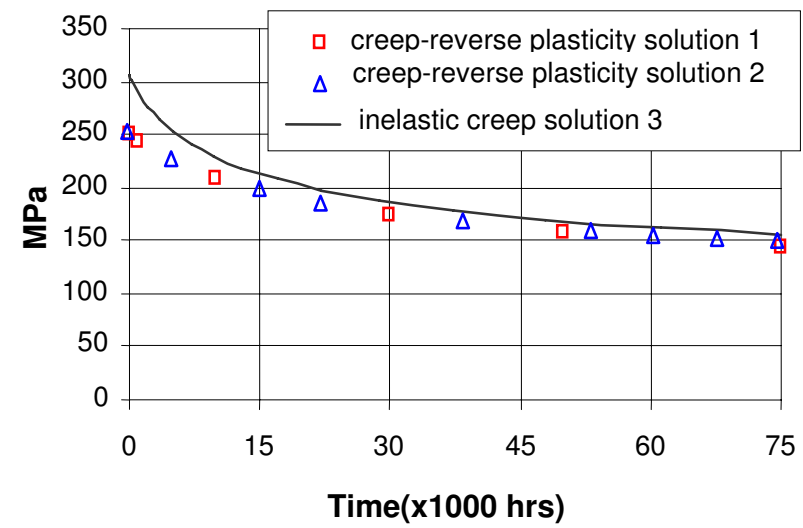

(b)

Fig. 10 The maximum flow stress with creep dwell time for a holed plate subjected to varying thermal loads from 0 to $0.8 \sigma_{t 0}$ (a) with constant $\dot{\varepsilon}_{0}$ using eqn (27A); (b) with temperature-dependent $\dot{\varepsilon}_{0}$ using eqn (27B) 


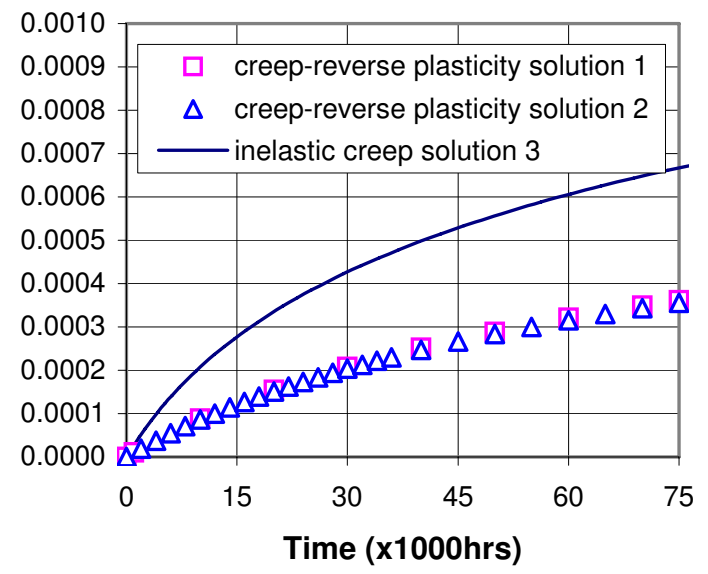

(a)

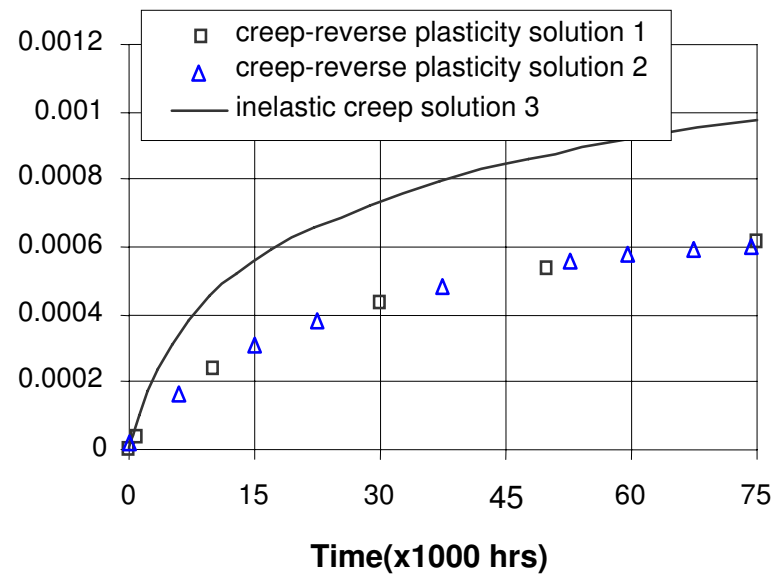

(b)

Fig. 11 The maximum creep strain with creep dwell time for a holed plate subjected to varying thermal loads from 0 to $0.8 \sigma_{t 0}$ (a) with constant $\dot{\varepsilon}_{0}$ using eqn (27A); (b) with temperature-dependent $\dot{\varepsilon}_{0}$ using eqn (27B)

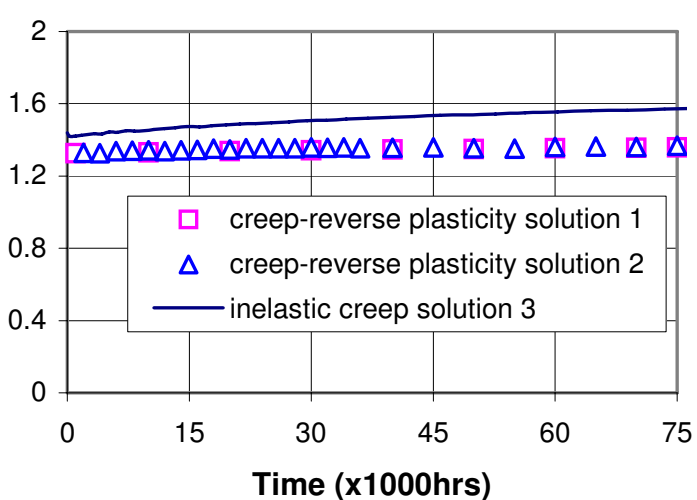

(a)

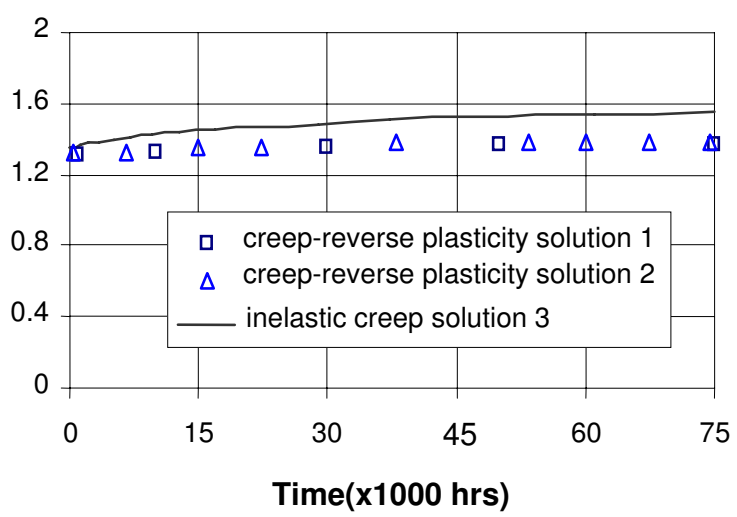

(b)

Fig. 12 The elastic follow-up factor $Z$ with creep dwell time for a holed plate subjected to varying thermal loads from 0 to $0.8 \sigma_{t 0}$ (a) with constant $\dot{\varepsilon}_{0}$ using eqn (27A); (b) with temperature-dependent $\dot{\varepsilon}_{0}$ using eqn (27B) 


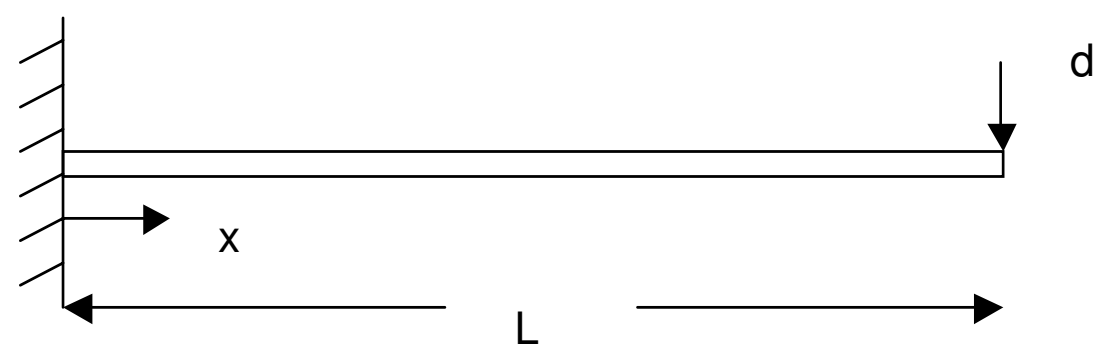

Figure A1 Configuration for Case 1 and 2

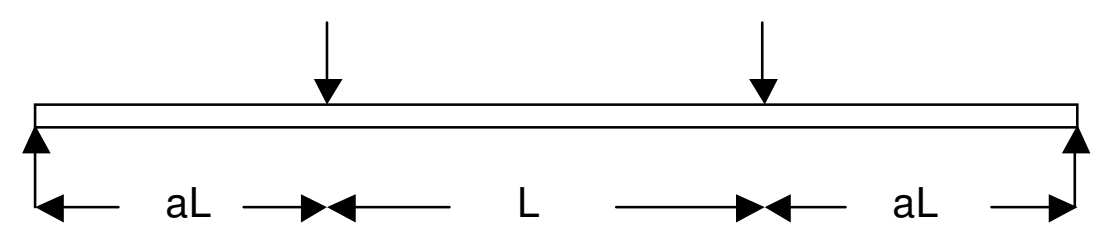

Figure A2 Beam under four point bending, Cases 3 and 4 